\section{QUALITY OF LIFE AS A PREDICTOR OF HOSPITALIZATION IN PATIENTS WITH CHRONIC KIDNEY DISEASE ON HEMODIALYSIS: A RETROSPECTIVE COHORT STUDY}

\author{
Thiago Dipp ${ }^{1,2}$, Gabriela Alves Pereira ${ }^{1}$, Karina Segatto ${ }^{1}$, \\ Maria Cristina dos Santos Baumgarten ${ }^{1}$, \\ Vanessa Biendruczak Silva ${ }^{1}$, Rodrigo Della Méa Plentz ${ }^{1}$
}

\section{ABSTRACT}

Introduction: As medical advances are achieved in the care of chronically ill patients, there is increasing evidence that health-related quality of life ( $Q \mathrm{oL})$ is associated with poor outcomes, including hospitalization and death. This study aimed to evaluate QoL as a predictor of hospitalization and death in patients with chronic kidney disease (CKD) on hemodialysis.

Methods: A retrospective cohort study of 108 patients with CKD on hemodialysis with 24-month follow-up. QoL was assessed by the Kidney Disease Quality of Life Short-Form (KDQOL-SF), including time to first hospitalization and death as outcomes.

Results: The highest KDQOL-SF scores at baseline were observed in Sexual function, Dialysis staff encouragement, and Cognitive function, while the lowest scores were observed in Working status, Role physical, and Energy/fatigue. There was an association of Overall health and Role emotional domains with shorter time to first hospitalization. Data analyzed were insufficient to indicate an association of QoL with mortality in this population.

Conclusion: QoL was associated with time to first hospitalization in patients with CKD on hemodialysis, but the results were not sufficient to indicate its association with mortality.

Keywords: Chronic kidney failure; renal dialysis; quality of life; survival analysis

Advances in medical care have extended not only the life expectancy but also the burden of illness and treatment of chronically ill patients, including those with chronic kidney disease (CKD). It is therefore increasingly important that health care providers pay close attention to patients' individual perceptions of their health, fitness, life satisfaction, and well-being ${ }^{1}$.

CKD is a global health burden that imposes high economic costs on health systems and has been considered an important and independent risk factor for cardiovascular disease ${ }^{2}$. Advanced CKD is characterized by irreversible renal injury that interferes directly with the normal hormonal, regulatory, and excretory functions of the kidneys. At this stage, renal replacement therapy with dialysis and/or kidney transplantation are required ${ }^{3}$. CKD has a consistent estimated global prevalence of $11 \%-13 \%$, with most cases classified as stage III2.

Hemodialysis, by replacing some missing functions of the kidney, also induces changes in other organs, including the neuromuscular, bone, cardiovascular, endocrine, immune, and respiratory systems $\mathrm{s}^{4}$. Patients usually have symptoms such as fatigue ${ }^{5}$, generalized muscle weakness ${ }^{6}$, low exercise tolerance ${ }^{4}$, erectile dysfunction ${ }^{7}$, decreased libido ${ }^{8}$, and reduced oxygen consumption ${ }^{9}$. These changes result in functional impairment, decreased work capacity, and dependence for activities of daily living ${ }^{4,8,10,11}$.
Clin Biomed Res. 2019;39(3):209-215

1 Universidade Federal de Ciências da Saúde de Porto Alegre (UFCSPA). Porto Alegre, RS, Brasil.

2 Universidade do Vale do Rio dos Sinos (Unisinos). São Leopoldo, RS, Brasil.

Corresponding author:

Thiago Dipp

thdipp@hotmail.com Universidade Federal de Ciências da Saúde de Porto Alegre (UFCSPA)

Rua Sarmento Leite, 245. 90050-170, Porto Alegre, RS, Brasil. 
Dipp et al.

CKD affects patients not only physically but also mentally, with patients reporting depressive symptoms ${ }^{12-14}$ that affect their mental and emotional health, with consequences to the general well-being and social behavior of individuals ${ }^{8}$. Depression has been associated with poor health-related quality of life (QoL) and negative outcomes, including worse morbidity and mortality in this population ${ }^{13,14}$.

QoL is a subjective perception of well-being that can be assessed by measuring symptoms, satisfaction, and treatment adherence ${ }^{11}$, and is based on the difference between patients' health expectations and experiences ${ }^{10,15-17}$. QoL in patients with chronic diseases has long been assessed solely in terms of survival and signs of the presence of the disease, without considering psychosocial and therapeutic implications ${ }^{11,18}$.

Specific instruments are used to assess certain aspects of QoL in populations with a specific disease, such as heart failure ${ }^{19}$, osteoarthritis ${ }^{20}$, and chronic obstructive pulmonary disease ${ }^{21}$. The Kidney Disease Quality of Life-Short Form (KDQOL-SF), a questionnaire that assesses particular health-related concerns of individuals with kidney disease by means of diseasetargeted items, was translated and validated for use in the Brazilian population ${ }^{18}$. This is an easily applied tool with reliable psychometric properties that can be used routinely in clinical practice ${ }^{18}$.

QoL assessment has been used for monitoring the efficiency of hemodialysis 22 and as a predictor of death ${ }^{17,23}$, hospitalization ${ }^{17,24}$, and progression of CKD to end stage ${ }^{23}$. A study conducted in the United States, European countries, and Japan involving patients with CKD on hemodialysis showed that low KDQOL-SF scores in physical, mental, and specific components of kidney disease are associated with increased risk of death and hospitalization in this population ${ }^{17}$. Determining reliable prognostic factors for mortality and morbidity is of great relevance in the clinical follow-up of these patients ${ }^{24}$. In Brazil, however, there is a lack of studies addressing QoL as an indicator of mortality and morbidity in patients with CKD. Therefore, the purpose of the present study was to evaluate QoL as a predictor of hospitalization and death in patients with CKD on hemodialysis with a follow-up of 24 months.

\section{METHODS}

This retrospective cohort study was approved by the Research Ethics Committee of Irmandade Santa Casa de Misericórdia de Porto Alegre (ISCMPA) (approval number 3453/10), Universidade Federal de Ciências da Saúde de Porto Alegre (UFCSPA) (approval number 551/10), and the Brazilian Clinical Trials Registry (registration number RBR-25TCRT). The sample consisted of patients with CKD on hemodialysis who were followed from January 2011 to December 2012. All participants provided written informed consent prior to inclusion in the study. Eligible participants were all patients aged $\geq 18$ years undergoing treatment for at least 3 months with 3 weekly sessions at the Outpatient Hemodialysis Unit of ISCMPA Santa Clara Polyclinic. Patients were selected by convenience sampling through oral invitation, regardless of ethnicity, sex, and level of education. Patients who were cognitively impaired and/or unable to answer the questionnaire were excluded from the study.

KDQOL-SF scores were analyzed in association with time to first hospitalization and survival time.

\section{Application of the KDQOL-SF}

The KDQOL-SF was applied by trained interviewers before the hemodialysis session for 2 consecutive years. The KDQOL-SF includes the SF-36 and 43 CKD-targeted items. The SF-36 consists of 36 items divided into 8 domains: Physical functioning, Role limitations caused by physical health problems, Role limitations caused by emotional health problems, Social functioning, Mental health, Pain, Vitality (Energy/fatigue), and Perceptions of general health and current health status compared to 1 year ago. CKD-targeted items are divided into 11 domains: Symptoms/problems, Effects of kidney disease on daily life, Burden of kidney disease, Working status, Cognitive function, Quality of social interaction, Sexual function, and Sleep. It also includes 3 additional QoL scales (Social support, Dialysis staff encouragement, and Patient satisfaction) and a final item to rate overall health on a 0-10 scale. The scores were calculated following the scoring procedure provided by the questionnaire for each domain, ranging from 0 to 100 , with higher scores indicating better $\mathrm{QoL}^{18}$.

\section{Biochemical evaluation}

Biochemical data were collected monthly as part of the hemodialysis unit routine. The data were then collected from the patients' electronic medical records according to the date corresponding to the QoL assessment and inclusion in the study and were used for sample characterization. All laboratory tests were performed at ISCMPA Central Laboratory.

\section{Evaluation of mortality and morbidity}

Data on survival time (mortality) and time to first hospitalization (morbidity) during follow-up were collected retrospectively from the patients' electronic medical records at ISCMPA Santa Clara Hospital or via a telephone contact protocol.

\section{Statistical analysis}

Descriptive variables were expressed as mean (standard deviation) or median (interquartile range), 
while categorical variables were expressed as absolute and relative frequencies. The Shapiro-Wilk test was used to determine the normality of data distribution. Spearman's correlation coefficients were calculated to test the correlation between KDQOLSF domain scores and hospitalization days. The relationship between predictors (KDQOL-SF domain scores) and outcomes (survival time and time to first hospitalization) was assessed through survival curves estimated by the Kaplan-Meier method. The sample was divided based on the median of KDQOL-SF domain scores by the log-rank (Mantel-Cox) test. An odds ratio (OR) analysis was performed to estimate the relative risk of predictors on outcomes. Data were analyzed using SPSS, version 19.0, and a $p$-value $<0.05$ was considered statistically significant.

\section{RESULTS}

Of 166 patients with CKD on hemodialysis in 2011, 108 were included in the study. Of these, 83 were followed up to 2012 and analyzed in this study. Figure 1 shows a flow chart of patient follow-up, including losses and exclusions during follow-up.

The clinical and biochemical characteristics of the sample at study entry are shown in Table 1.

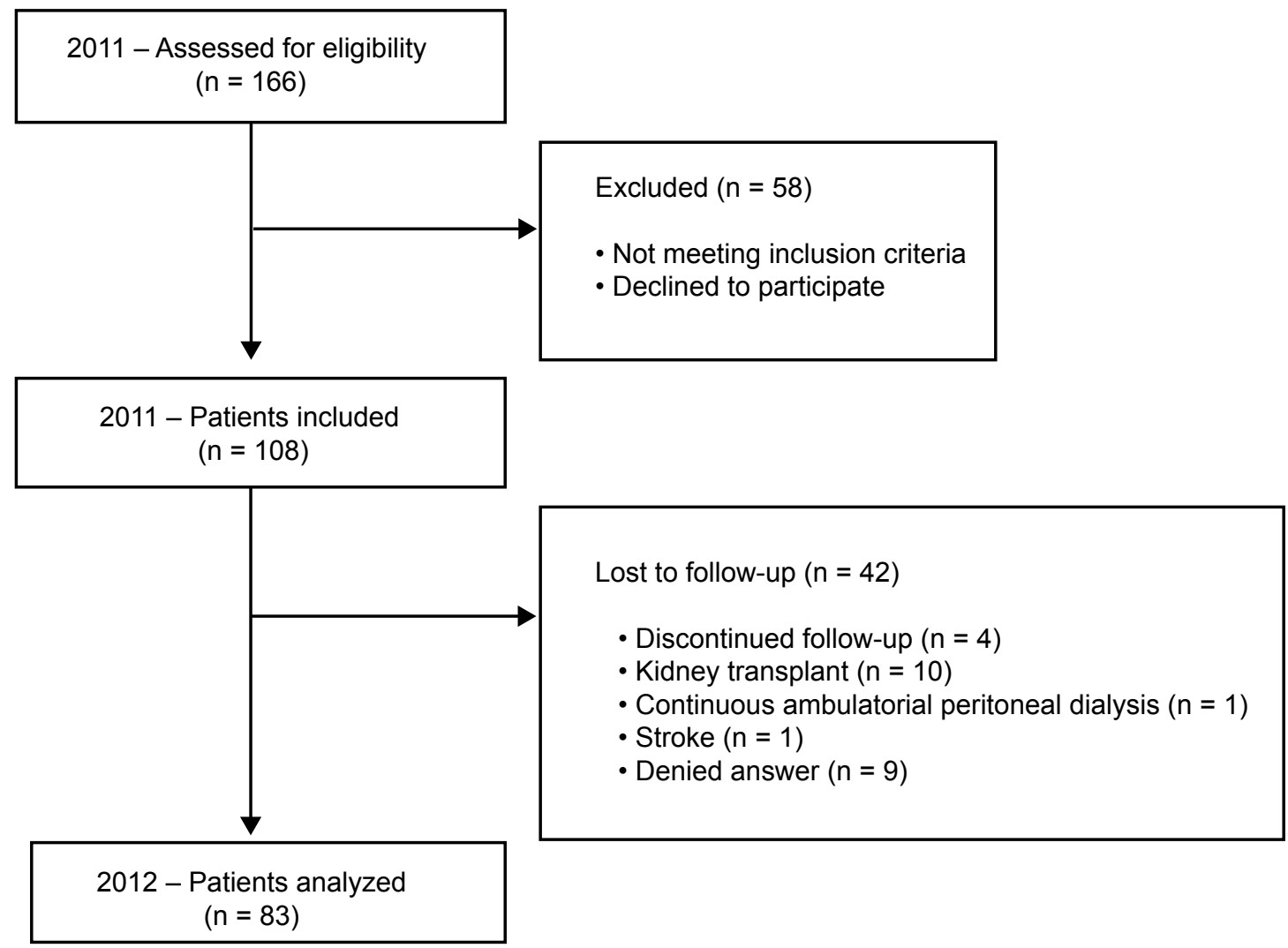

Figure 1: Flow chart of patient follow-up with losses and exclusions during follow-up.

During the 24-month follow-up period, $12(11.1 \%)$ patients died due to CKD complications, $5(4.6 \%)$ were admitted for CKD complications, and $10(9.2 \%)$ underwent a kidney transplant. Hospitalization time was 20 (12-29) days at baseline.

The highest KDQOL-SF scores at baseline were observed in the Sexual function (93.75 [75-100]), Dialysis staff encouragement (87.5 [62.5-100]), and Cognitive function (86.67 [80-100]) domains, while the lowest scores were observed in the Working status (25 [0-50]), Role physical (50 [0-75]), and Energy/ fatigue (57.5 [33.75-75]) domains. No correlation was found between KDQOL-SF domain scores and hospitalization days.

Figure 2 shows Kaplan-Meier survival curves for time to first hospitalization and survival time during the 24-month follow-up period. There was a significant difference in the estimated time to first hospitalization between patients with values above and below the median scores in Overall health $(11 \times 6$ months, $p=0.04)$ and Role emotional $(11 \times 8$ months, $p=0.007)$. 
Dipp et al.

Table 1: Clinical and biochemical characteristics of patients with CKD at study entry $(n=108)$.

\begin{tabular}{lc}
\hline Male/Female (\%) & $\mathbf{6 0 / 4 0}$ \\
\hline Age (years) & $54.8 \pm 15.1$ \\
Dialysis time (months) & $60[36-102]$ \\
Creatinine (mg/dL) & $9.8[7.45-11.6]$ \\
Pre-dialysis urea (mg/dL) & $154.6 \pm 45.8$ \\
Glucose (mg/dL) & $95[82-111]$ \\
Cholesterol (mg/dL) & $148.2 \pm 37.2$ \\
Triglycerides (mg/dL) & $140[91-179.5]$ \\
\hline
\end{tabular}

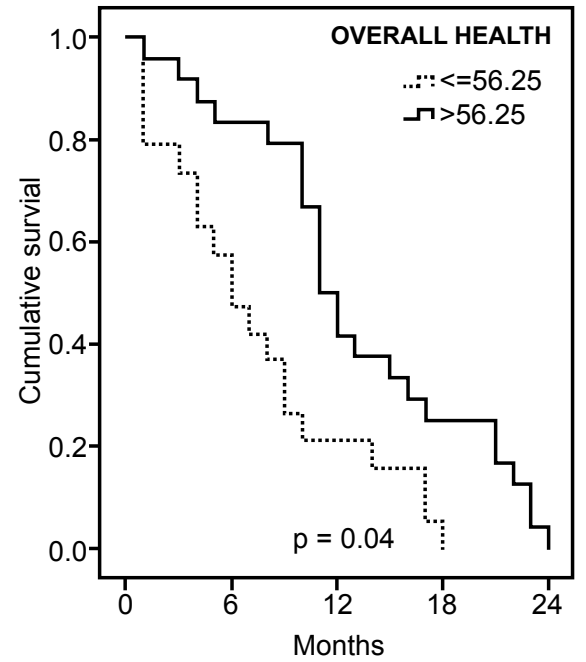

Table 1: Continuation

\begin{tabular}{|c|c|}
\hline Male/Female (\%) & $60 / 40$ \\
\hline Hemoglobin (g/dL) & $11.2 \pm 2.1$ \\
\hline Erythrocytes (millions $/ \mu \mathrm{L}$ ) & $3.85 \pm 1.2$ \\
\hline $\begin{array}{l}\text { Glutamic oxaloacetic } \\
\text { transaminase }(\mathrm{u} / \mathrm{L})\end{array}$ & $18.5[16-26]$ \\
\hline $\begin{array}{l}\text { Glutamic pyruvic } \\
\text { transaminase (u/L) }\end{array}$ & $16[11-21]$ \\
\hline Parathyroid hormone (pg/mL) & $444.9[193.4-881.3]$ \\
\hline
\end{tabular}

$\mathrm{CKD}=$ chronic kidney disease.

Data are expressed as mean \pm standard deviation or median and interquartile range (25th-75th).

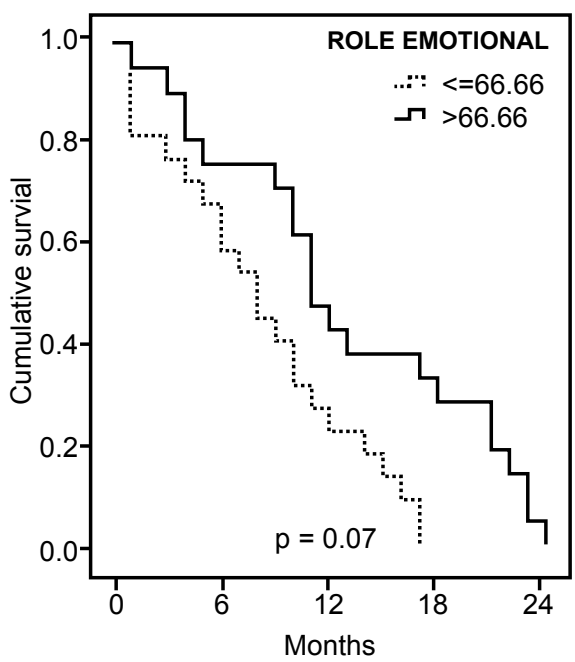

Figure 2: Kaplan-Meier survival curves until first hospitalization during the 24-month follow-up period. Table 2 shows the median scores and $95 \%$ confidence intervals for all domains, in addition to the estimated time to first hospitalization (in days) and survival time (in months).

Table 2: Analysis of survival and hospitalization by the Kaplan-Meier method according to the median of KDQOL-SF domain scores by the log-rank (Mantel-Cox) test.

\begin{tabular}{|c|c|c|c|c|c|c|c|c|}
\hline \multirow{2}{*}{ KDQOL-SF domain } & \multicolumn{5}{|c|}{ Hospitalization } & \multicolumn{3}{|c|}{ Survival } \\
\hline & Median & $95 \% \mathrm{Cl}$ & Estimate & & $p$ & $95 \% \mathrm{Cl}$ & Estimate & $\boldsymbol{P}$ \\
\hline Symptoms/ problems & $\begin{array}{l}\leq 82.81 \\
>82.81\end{array}$ & $\begin{array}{l}7.7-12.2 \\
9.5-12.4\end{array}$ & $\begin{array}{l}10.0 \\
11.0\end{array}$ & 0.552 & 0.552 & $\begin{array}{l}9.3-18.6 \\
0.0-24.0\end{array}$ & $\begin{array}{l}14.0 \\
12.0\end{array}$ & 0.192 \\
\hline $\begin{array}{l}\text { Effects of kidney } \\
\text { disease on daily life }\end{array}$ & $\begin{array}{c}<=72.66 \\
>72.66\end{array}$ & $\begin{array}{l}7.7-12.2 \\
8.8-13.1\end{array}$ & $\begin{array}{l}10.0 \\
11.0\end{array}$ & 0.778 & 0.778 & $\begin{array}{l}7.0-20.9 \\
3.6-20.3\end{array}$ & $\begin{array}{l}14.0 \\
12.0\end{array}$ & 0.512 \\
\hline $\begin{array}{l}\text { Burden of kidney } \\
\text { disease }\end{array}$ & $\begin{array}{l}<=50 \\
>50\end{array}$ & $\begin{array}{l}5.8-12.1 \\
9.9-12.0\end{array}$ & $\begin{array}{c}9.0 \\
11.0\end{array}$ & 0.217 & 0.217 & $\begin{array}{l}13.6-22.3 \\
7.6-16.3\end{array}$ & $\begin{array}{l}18.0 \\
12.0\end{array}$ & 0.009 \\
\hline Working status & $\begin{array}{c}<=25 \\
>25\end{array}$ & $\begin{array}{l}6.4-11.5 \\
9.7-12.2\end{array}$ & $\begin{array}{c}9.0 \\
11.0\end{array}$ & 0.372 & 0.372 & $\begin{array}{l}7.4-16.5 \\
3.2-26.7\end{array}$ & $\begin{array}{l}12.0 \\
15.0\end{array}$ & 0.985 \\
\hline Cognitive function & $\begin{array}{c}<=86.67 \\
>86.67\end{array}$ & $\begin{array}{l}7.6-12.3 \\
7.4-12.5\end{array}$ & $\begin{array}{l}10.0 \\
10.0\end{array}$ & 0.760 & 0.760 & $\begin{array}{l}7.9-22.0 \\
3.9-20.0\end{array}$ & $\begin{array}{l}15.0 \\
12.0\end{array}$ & 0.297 \\
\hline $\begin{array}{l}\text { Quality of social } \\
\text { interaction }\end{array}$ & $\begin{array}{c}<=85 \\
>85\end{array}$ & $\begin{array}{l}6.4-13.5 \\
8.2-11.7\end{array}$ & $\begin{array}{l}10.0 \\
10.0\end{array}$ & 0.751 & 0.751 & $\begin{array}{c}4.8-15.1 \\
13.1-22.8\end{array}$ & $\begin{array}{l}10.0 \\
18.0\end{array}$ & 0.149 \\
\hline Sexual function & $\begin{array}{c}<=93.75 \\
>93.75\end{array}$ & $\begin{array}{c}7.6-26.3 \\
10.1- \\
11.8\end{array}$ & $\begin{array}{l}17.0 \\
11.0\end{array}$ & 0.454 & 0.454 & $\begin{array}{l}14.0-21.9 \\
3.5-16.4\end{array}$ & $\begin{array}{l}18.0 \\
10.0\end{array}$ & 0.070 \\
\hline
\end{tabular}


Quality of life and hospitalization in hemodialysis patients

Table 2: Continuation

\begin{tabular}{|c|c|c|c|c|c|c|c|c|}
\hline \multirow{2}{*}{ KDQOL-SF domain } & \multicolumn{5}{|c|}{ Hospitalization } & \multicolumn{3}{|c|}{ Survival } \\
\hline & Median & $95 \% \mathrm{Cl}$ & Estimate & & $p$ & $95 \% \mathrm{Cl}$ & Estimate & $P$ \\
\hline Sleep & $\begin{array}{c}<=71.25 \\
>71.25\end{array}$ & $\begin{array}{l}5.5-14.4 \\
8.1-11.8\end{array}$ & $\begin{array}{l}10.0 \\
10.0\end{array}$ & 0.248 & 0.248 & $\begin{array}{l}7.0-20.9 \\
4.6-19.3\end{array}$ & $\begin{array}{l}14.0 \\
12.0\end{array}$ & 0.595 \\
\hline Social support & $\begin{array}{c}<=83.33 \\
>83.33\end{array}$ & $\begin{array}{l}7.3-12.6 \\
6.2-11.7\end{array}$ & $\begin{array}{c}10.0 \\
9.0\end{array}$ & 0.908 & 0.908 & $\begin{array}{l}7.6-16.3 \\
6.1-29.8\end{array}$ & $\begin{array}{l}12.0 \\
18.0\end{array}$ & 0.289 \\
\hline $\begin{array}{l}\text { Dialysis staff } \\
\text { encouragement }\end{array}$ & $\begin{array}{c}<=87.50 \\
>87.50\end{array}$ & $\begin{array}{l}2.5-11.4 \\
9.4-12.5\end{array}$ & $\begin{array}{c}7.0 \\
11.0\end{array}$ & 0.431 & 0.431 & $\begin{array}{c}1.2-22.7 \\
11.7-24.2\end{array}$ & $\begin{array}{l}12.0 \\
18.0\end{array}$ & 0.149 \\
\hline Patient satisfaction & $\begin{array}{c}<=66.67 \\
>66.67\end{array}$ & $\begin{array}{l}5.8-12.1 \\
8.8-13.1\end{array}$ & $\begin{array}{c}9.0 \\
11.0\end{array}$ & 0.560 & 0.560 & $\begin{array}{c}0.0-25.9 \\
10.3-17.6\end{array}$ & $\begin{array}{l}12.0 \\
14.0\end{array}$ & 0.255 \\
\hline Physical functioning & $\begin{array}{c}<=70 \\
>70\end{array}$ & $\begin{array}{l}6.2-11.7 \\
9.9-12.0\end{array}$ & $\begin{array}{c}9.0 \\
11.0\end{array}$ & 0.124 & 0.124 & $\begin{array}{l}7.0-20.9 \\
3.6-20.3\end{array}$ & $\begin{array}{l}14.0 \\
12.0\end{array}$ & 0.215 \\
\hline Role physical & $\begin{array}{l}<=50 \\
>50\end{array}$ & $\begin{array}{l}6.5-11.4 \\
9.6-12.3\end{array}$ & $\begin{array}{c}9.0 \\
11.0\end{array}$ & 0.112 & 0.112 & $\begin{array}{l}8.1-19.8 \\
7.3-22.6\end{array}$ & $\begin{array}{l}14.0 \\
15.0\end{array}$ & 0.824 \\
\hline Pain & $\begin{array}{c}<=63.13 \\
>63.13\end{array}$ & $\begin{array}{l}5.7-14.2 \\
8.4-11.6\end{array}$ & $\begin{array}{l}10.0 \\
10.0\end{array}$ & 0.857 & 0.857 & $\begin{array}{l}8.6-19.3 \\
2.8-37.1\end{array}$ & $\begin{array}{l}14.0 \\
20.0\end{array}$ & 0.062 \\
\hline Overall health & $\begin{array}{c}<=56.25 \\
>56.25\end{array}$ & $\begin{array}{c}3.1-8.8 \\
9.4-12.6\end{array}$ & $\begin{array}{c}6.0 \\
11.0\end{array}$ & 0.04 & 0.04 & $\begin{array}{l}8.8-19.1 \\
9.6-26.3\end{array}$ & $\begin{array}{l}14.0 \\
18.0\end{array}$ & 0.640 \\
\hline Emotional well-being & $\begin{array}{c}<=74 \\
>74\end{array}$ & $\begin{array}{l}6.3-11.9 \\
9.2-14.9\end{array}$ & $\begin{array}{c}8.0 \\
11.0\end{array}$ & 0.284 & 0.284 & $\begin{array}{c}12.3-18.4 \\
7.9-17.4\end{array}$ & $\begin{array}{l}15.0 \\
12.0\end{array}$ & 0.586 \\
\hline Role emotional & $\begin{array}{c}<=66.66 \\
>66.66\end{array}$ & $\begin{array}{l}4.5-11.4 \\
8.7-13.2\end{array}$ & $\begin{array}{c}8.0 \\
11.0\end{array}$ & 0.007 & 0.007 & $\begin{array}{l}8.5-21.4 \\
1.2-22.7\end{array}$ & $\begin{array}{l}15.0 \\
12.0\end{array}$ & 0.793 \\
\hline Social functioning & $\begin{array}{c}<=75 \\
>75\end{array}$ & $\begin{array}{l}6.6-13.3 \\
8.1-11.8\end{array}$ & $\begin{array}{l}10.0 \\
10.0\end{array}$ & 0.351 & 0.351 & $\begin{array}{l}9.8-18.1 \\
0.9-23.0\end{array}$ & $\begin{array}{l}14.0 \\
12.0\end{array}$ & 0.979 \\
\hline Energy/fatigue & $\begin{array}{c}<=57.5 \\
>57.5\end{array}$ & $\begin{array}{c}7.6-12.4 \\
10.0- \\
11.9 \\
\end{array}$ & $\begin{array}{l}10.0 \\
11.0\end{array}$ & 0.797 & 0.797 & $\begin{array}{c}12.4-17.5 \\
9.0-14.9\end{array}$ & $\begin{array}{l}15.0 \\
12.0\end{array}$ & 0.769 \\
\hline
\end{tabular}

KDQOL-SF = Kidney Disease Quality of Life-Short Form; $95 \% \mathrm{Cl}=95 \%$ confidence interval; $p<0.05$.

\section{DISCUSSION}

The present study demonstrated that QoL can predict adverse outcomes, such as hospitalization. Among patients with CKD on hemodialysis, lower scores in KDQOL-SF Overall health and Role emotional domains were associated with shorter time to first hospitalization. As for survival time, despite a possible trend toward shorter survival with lower scores in the Pain domain, the data analyzed were insufficient to prove the indication of QoL as a predictor of mortality in this population.

In a previous study using the KDQOL-SF, lower scores in the 3 major components of the questionnaire (physical, mental, and specific components of kidney disease) were associated with higher risk of death and hospitalization in patients on hemodialysis ${ }^{17}$. Physical-related questionnaire domains have shown greater influence on mortality rates ${ }^{17,25}$, in addition to a strong association with progression to end-stage renal disease ${ }^{23}$. Therefore, the KDQOL-SF is an important tool because it includes specific aspects of kidney disease, making it more sensitive in detecting possible changes in patients' health status ${ }^{18,26}$ as well as a reliable instrument to measure QoL in patients on hemodialysis ${ }^{27}$.

Our findings are consistent with an earlier study conducted in Brazil reporting that lower scores in the Overall health domain seem to be related to patients on hemodialysis feeling sick all the time, mostly because of nutritional restrictions, medications, and vascular access care ${ }^{27}$. Lower scores in KDQOL-SF domains have also been related to an increased number of associated diseases and time spent on hemodialysis ${ }^{28}$. An association has also been observed between lower QoL in patients with CKD and sociodemographic and clinical factors, such as higher consumption of medicines, more frequent hospitalizations, and a larger number of associated chronic diseases ${ }^{17,25,28}$. Subjective measures, such as questionnaire application, are associated with the physical condition of patients with CKD and 
may represent, at least in part, the low physical and functional performance of these patients ${ }^{29}$.

A cohort study with a follow-up of 12 months and QoL assessment by the SF-36 showed a correlation between hospitalization days and Physical functioning, Overall health, and Vitality, but no significant difference was found in survival curves ${ }^{24}$. In our study, although KDQOL-SF domain scores did not correlate with hospitalization days, they were able to demonstrate the influence of QoL domains on morbidity in the study population. Therefore, QoL assessment should be included in health care intervention programs for patients with kidney disease by using validated, disease-specific instruments in this population, such as the KDQOL-SF.

The survival of patients with CKD on hemodialysis is influenced by the presence of diabetes and older age at the start of the dialysis program, without direct influence of sex or ethnicity ${ }^{30}$. The mortality rate in our study was $16 \%$, more significant than that of a previous study ( $12 \%$ in 12 months $)^{24}$, a result that is primarily related to the follow-up period of 24 months used in our study. A 25-year retrospective cohort study reported a mortality rate of $32.5 \%$, which is significantly higher than that observed in our study probably because of a longer follow-up and larger sample ${ }^{30}$. It is worth noting that, in our study, $11 \%$ of patients underwent a kidney transplant, in contrast to only $1.8 \%$ in the above-mentioned 12-month follow-up study ${ }^{24}$, which may partly be explained by the fact that data from our institution, ISCMPA, serve as a reference for the annual number of transplants performed in the country.

The present study has some limitations, such as the short follow-up period and the fact that data on mortality and hospitalization were collected retrospectively from medical records and by telephone contact. Further prospective studies are warranted to confirm our findings. In addition, variables known to be associated with mortality in patients with CKD were not included in the statistical analysis, such as age, diagnosis of diabetes mellitus, dialysis efficacy (Kt/v or URR), hyperphosphatemia, anemia, and Charlson comorbidity index. Also, multiple logistic regression models and potential confounders were not explored, preventing us from determining predictive effects on hospitalization and mortality with the use of QoL assessment.

QoL assessed by the KDQOL-SF is an important tool for monitoring patients and dialysis treatment. The results suggest that QoL measures can be used to identify patients potentially at risk for negative outcomes. It is also important to assess whether interventions that improve QoL also decrease the risk of death and hospitalization among patients on hemodialysis.

\section{Acknowledgments}

We are grateful to ISCMPA, in particular to the Nephrology Service of Santa Clara Hospital for allowing us to complete the study; to the medical staff, nursing staff, employees, and patients for participation in the study; and to the statistical consultant Cristiane Bundchen for assistance in the analyses. We would also like to thank the Coordenação de Aperfeiçoamento de Pessoal de Nível Superior (CAPES), Conselho Nacional de Desenvolvimento Científico e Tecnológico (CNPq) and Fundação de Amparo à Pesquisa do Estado do Rio Grande do Sul (FAPERGS) for the grants provided.

\section{Conflicts of interest}

The authors declare no conflicts of interest.

\section{REFERENCES}

1. Mitema D, Jaar BG. How can we improve the quality of life of dialysis patients? Semin Dial. 2016;29(2): 93-102.

2. Hill NR, Fatoba ST, Oke JL, Hirst JA, O'Callaghan CA, Lasserson DS, Hobbs FD. Global prevalence of chronic kidney disease - a systematic review and meta-analysis. PLoS One. 2016;11(7):e0158765.

3. Lima MC, Cicotoste CL, Cardoso KS, Forgiarini LA, Monteiro MB, Dias AS. Effect of exercise performed during hemodialysis: strength versus aerobic. Ren Fail. 2013;35(5):697-704.
4. Coelho DM, Castro AM, Tavares HA, Abreu PCB, Glória RR, Duarte $\mathrm{MH}$, Oliveira MR. Efeitos de um programa de exercícios físicos no condicionamento de pacientes em hemodiálise. J Bras Nefrol. 2006;28(3):121-7.

5. Gómez-Fernández P, Sánchez Agudo L Calatrava JM, Escuin F, Selgas R, Martinez ME, et al. Respiratory muscle weakness in uremic patients under continuous ambulatory peritoneal dialysis. Nephron. 1984;36(4):219-23.

6. Bohannon RW, Hull D, Palmeri D. Muscle strength impairments and gait performance deficits in kidney transplantation candidates. $\mathrm{Am} \mathrm{J}$ Kidney Dis. 1994;24(3):480-5.
7. Toorians AW, Janssen E, Laan E, Gooren LJ, Giltay EJ, Oe PL, et al. Chronic renal failure and sexual functioning: clinical status versus objectively assessed sexual response. Nephrol Dial Transplant. 1997;12(12):2654-63.

8. Schardong TJ, Lukrafka JL, Garcia VD. Avaliação da função pulmonar e da qualidade de vida em pacientes com doença renal crônica submetidos à hemodiálise. J Bras Nefrol. 2008;30(1):40-7.

9. Johansen KL. Exercise and chronic kidney disease: current recommendations. Sports Med. 2005;35(6):485-99. 
10. Groothoff JW, Grootenhuis MA, Offringa M, Gruppen MP, Korevaar JC, Heymans HS. Quality of life in adults with end-stage renal disease since childhood is only partially impaired. Nephrol Dial Transplant. 2003;18(2):310-7.

11. Martins MRI, Cesarino CB. Qualidade de vida de pessoas com doença renal crônica em tratamento hemodialítico. Rev Latino-Am Enferm. 2005;13(5):670-6.

12. Lopes AA, Bragg J, Young E, Goodkin D, Mapes D, Combe C, et al. Depression as a predictor of mortality and hospitalization among hemodialysis patients in the United States and Europe. Kidney Int. 2002;62(1):199-207.

13. Palmer SC, Vecchio M, Craig JC, Tonelli M, Johnson DW, Nicolucci A, et al. Association between depression and death in people with CKD: a meta-analysis of cohort studies. Am J Kidney Dis. 2013;62(3):493-505.

14. Boulware LE, Liu Y, Fink NE, Coresh J, Ford DE, Klag MJ, Powe NR. Temporal relation among depression symptoms, cardiovascular disease events, and mortality in end-stage renal disease: contribution of reverse causality. Clin J Am Soc Nephrol. 2006;1(3):496-504.

15. Carr AJ, Gibson B, Robinson PG. Measuring quality of life: is quality of life determined by expectations or experience? BMJ. 2001;322(7296):1240-3.

16. Fujisawa M, Ichikawa $Y$, Yoshiya $K$, Isotani S, Higuchi A, Nagano S, et al. Assessment of health-related quality of life in renal transplant and hemodialysis patients using the SF-36 health survey. Urology. 2000;56(2):201-6.
17. Mapes DL, Lopes AA, Satayathum S, McCullough KP, Goodkin DA, Locatelli $F$, et al. Health-related quality of life as a predictor of mortality and hospitalization: the Dialysis Outcomes and Practice Patterns Study (DOPPS). Kidney Int. 2003;64(1):339-49.

18. Duarte PS, Miyazaki MCOS, Ciconelli RM, Sesso R. Tradução e adaptação cultural do instrumento de avaliação de qualidade de vida para pacientes renais crônicos (KDQOL-SF $\left.{ }^{\mathrm{TM}}\right)$. Rev Assoc Med Bras. 2003;49(4):375-81.

19. Carvalho VO, Guimarães GV, Carrara D, Bacal F, Bocchi EA. Validation of the portuguese version of the minnesota living with heart failure questionnaire. Arq Bras Cardiol. 2009;93(1):39-44.

20. Cantarelli FB, Simões MFJ, Oliveira LM, Ferraz MB, Szejnfeld VL. Qualidade de vida em pacientes com fraturas por osteoporose: adaptação cultural, reprodutibilidade e validação do Osteoporosis Assessment Questionnaire (OPAQ). Rev Bras Reumatol. 1999;39(1):9-18.

21. Sousa TC, Jardim JR, Jones P. Validação do questionário do Hospital Saint George na Doença Respiratória (SGRQ) em pacientes portadores de doença pulmonar obstrutiva crônica no Brasil. J Pneumologia. 2000;26(3):119-28.

22. Merkus MP, Jager KJ, Dekker FW, Haan RJ, Boeschoten EW, Krediet RT. Predictors of poor outcome in chronic dialysis patients: the Netherlands Cooperative Study on the Adequacy of Dialysis. The NECOSAD Study Group. Am J Kidney Dis. 2000;35(1):69-79.

23. Tsai YC, Hung CC, Hwang SJ, Wang SL, Hsiao SM, Lin MY, et al. Quality of life predicts risks of endstage renal disease and mortality in patients with chronic kidney disease. Nephrol Dial Transplant. 2010;25(5):1621-6.

24. Santos PR. Associação de qualidade de vida com hospitalização e óbito em pacientes portadores de doença renal crônica em hemodiálise. J Bras Nefrol. 2005;27(4)-184-90.

25. DeOreo PB. Hemodialysis patientassessed functional health status predicts continued survival, hospitalization, and dialysisattendance compliance. Am J Kidney Dis. 1997;30(2):204-12.

26. Cagney KA, Wu AW, Fink NE, Jenckes MW, Meyer KB, Bass EB, Powe NR. Formal literature review of quality-of-life instruments used in endstage renal disease. Am J Kidney Dis. 2000;36(2):327-36.

27. Cavalcante MCV, Lamy ZC, Lamy Filho F, França AKTC, Santos AM, Thomaz EBAF, et al. Fatores associados à qualidade de vida de adultos em hemodiálise em uma cidade do nordeste do Brasil. $J$ Bras Nefrol. 2013;35(2):79-86.

28. Braga SFM, Peixoto SV, Gomes IC, Acúrcio FA, Andrade EIG, Cherchiglia ML. Fatores associados com a qualidade de vida relacionada à saúde de idosos em hemodiálise. Rev Saude Publica. 2011;45(6):1127-36.

29. Baumgartem MC, Dipp T, Silva VG, Giacomazzi CM, Segatto K, Pereira GA, et al. Percepção subjetiva e desempenho físico de pacientes com doença renal crônica em hemodiálise. Rev Acta Bras do Mov Hum.2012;2(1):5-14.

30. Silva LAM, Mezzomo NF, Henry Mor P, Arantes LC, Rempel W, Argenta LC, et al. Sobrevida em hemodiálise crônica: estudo de uma coorte de 1.009 pacientes em 25 anos. J Bras Nefrol. 2009;31(3):190-7. 